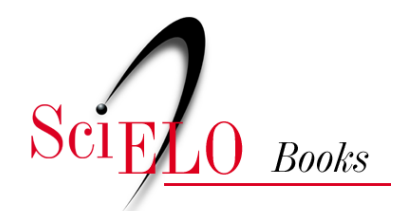

\title{
"Até os penhascos duros respondem" Breve introdução à epistolografia de Antônio Vieira
}

\author{
Ana Lúcia Machado de Oliveira
}

\section{SciELO Books / SciELO Livros / SciELO Libros}

OLIVEIRA, A.L.M. “Até os penhascos duros respondem”: Breve introdução à epistolografia de Antônio Vieira. In: WERKEMA, A.S., ROCHA, F.C.D., and OLIVEIRA, L.D., eds. Literatura brasileira em foco VIII: outras formas de escrita [online]. Rio de Janeiro: EdUERJ, 2018, pp. 46-62. ISBN 978-85-7511-487-2. https://doi.org/10.7476/9788575114872.0004.

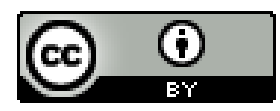

All the contents of this work, except where otherwise noted, is licensed under a Creative Commons Attribution 4.0 International license.

Todo o conteúdo deste trabalho, exceto quando houver ressalva, é publicado sob a licença Creative Commons Atribição 4.0.

Todo el contenido de esta obra, excepto donde se indique lo contrario, está bajo licencia de la licencia $\underline{\text { Creative Commons }}$ Reconocimento 4.0. 
Ana Lúcia Machado de Oliveira

\section{"Até os penhascos duros respondem":1 Breve introdução à epistolografia de Antônio Vieira}

1 Trata-se de fragmento de carta endereçada à nobreza de Portugal, de 31 de julho de 1694, em que se lê: "É cousa tão natural o responder, que até os penhascos duros respondem, e para as vozes têm ecos. Pelo contrário é tão grande violência não responder, que aos que nasceram mudos fez a natureza também surdos, porque se ouvissem, e não pudessem responder, rebentariam de dor" (VIEIRA, 2014, t. I, vol. IV, p. 499). 
As cartas de Vieira não são informais e não se podem ler como depósitos neutros de informações positivas sobre acontecimentos do século XVII. Seu eventual leitor as lerá mal ou parcialmente, se não observar que sua forma é modelada por categorias retórico-poéticas da preceptiva epistolar e teológico-políticas da doutrina católica da monarquia absolutista (Hansen, 2003, pp. 14-5).

Não pretendo aqui desenvolver um estudo aprofundado da epistolografia do jesuíta português Antônio Vieira, mas apenas levantar alguns pontos que funcionem como porta de acesso, para neófitos, a essa copiosa e relevante produção textual, constituída até o presente por cerca de 750 peças que ainda não mereceram atenção suficiente por parte da crítica. Como se sabe, esta foi uma prática letrada muito utilizada pelo inaciano no decurso de toda sua longa vida, desde a sua primeira missiva conhecida, a carta ânua dirigida em 1626 ao Geral da Companhia de Jesus em Roma, ${ }^{2}$ até a última, ditada dias antes de sua morte, em 1697, e igualmente endereçada ao Geral dos jesuítas. Além de sua troca epistolar com membros do clero, Vieira se correspondeu igualmente com figuras bastante influentes na vida

2 Para uma análise da carta ânua vieiriana, consultar: Oliveira, 2008, pp. 137-54. 
política e diplomática lusitana da segunda metade do século XVII, dentre as quais se incluem reis, membros da família real e da nobreza.

Importa destacar que essa vasta produção fornece indicações preciosas sobre o percurso biográfico do autor - lugares visitados, atividades realizadas, relações que manteve - e nos oferece ainda numerosas informações sobre o tempo em que viveu, segundo o próprio jesuíta afirma no final da vida, em carta a Francisco de Brito Freire: "Que novas darei de mim a Vossa Senhoria, depois de tantos anos, senão que ainda vivo? Parece que me guarda Deus para testemunha da variedade e mudança do mundo neste século, depois de ter corrido e visto tanta parte dele" (Vieira, 2014, tomo I, vol. IV, p. 445, grifos meus).

Antes de iniciar o exame específico das cartas vieirianas, é fundamental tecer breves considerações acerca da inserção desse gênero na longa tradição da ars dictaminis, a descrição medieval da arte de composição em prosa e, mais especificamente, da escrita de cartas, segundo uma prática ligada ao estudo da retórica, tal como foi sistematizada na Idade Média. Sabe-se que a carta também foi utilizada na Antiguidade, mas sem ganhar o estatuto de um gênero de discurso e, por isso, não foi tratada especificamente nas artes retóricas desse período. James Murphy, em sua relevante obra Rhetoric in the Middle Ages, nos informa que só no quarto século da era cristã iniciou-se uma discussão sobre a epistola, na obra Ars rhetorica, do romano Julius Victor, que a relaciona ao sermo, ou discurso informal, considerando-a um tipo de conversação entre pessoas ausentes (Murphy, 1990, p. 195). Para os propósitos deste trabalho, importa destacar sua distinção entre dois tipos de cartas: as negotiales, que tratam de temas de interesse geral, por isso admitem a dissertação, a erudição e os ornamentos, além de uma extensão maior; e as fami- 
liares, que abordam assuntos particulares, aplicando um estilo mais simples.

Segundo Murphy, o nascimento da ars dictaminis e seu estilo correlato, denominado cursus ou ritmo da prosa, está relacionado ao monge beneditino italiano Alberico de Monte Cassino, o primeiro a relacionar retórica e escrita de cartas num tratado formal sobre essa nova arte, no século XI, retomando as partes do discurso estudadas por Cícero e articulando-as à composição epistolar. Em suas obras Dictaminum radii (ou Flores rhetorici) e Breviarium de dictamine, o beneditino nos apresenta os elementos centrais da ars dictaminis: a relação da retórica com a escrita epistolar, a padronização das partes de uma carta, a ênfase nas seções introdutória e de saudação com a distinção entre níveis sociais dos destinatários, a inclusão de modelos de cartas e formas oficiais (cf. Murphy, 1990, p. 210).

Alguns anos depois, o centro da reflexão acerca desse gênero discursivo passou a ser a cidade italiana de Bolonha, em que vários autores desenvolveram trabalhos sobre essa arte que permaneceram modelares durante vários séculos. Dentre as primeiras teorizações sobre a composição de cartas, surgidas no século XII, se destaca a do denominado Anônimo de Bolonha, cujas Rationes dictandi datam do ano de 1135. Em tais regras, especifica-se a divisão mais habitual de uma carta em cinco partes: saudação, captação da benevolência, narração, petição e conclusão (Tin, 2005, pp. 83-101). Para ressaltar o grau de formalidade presente na codificação medieval do gênero, basta mencionar que, nessa obra, enumeram-se dezessete tipos de saudação, determinados pela relação estabelecida entre o remetente e o destinatário no âmbito das práticas sociais. Assim, há modelos de saudação adequada, por exemplo, entre senhores e súditos, súditos e senhores, eclesiásticos, senhores a subordinados culpáveis e até mesmo de filhos delinquentes aos pais. Deve-se destacar que, nesse 
pequeno tratado de cerca de trinta páginas, é precisamente a saudação que recebe o tratamento mais minucioso, o que evidencia o valor das relações de subordinação sempre reiteradas pelos diversos modos de saudar. ${ }^{3}$

A partir do século XIV, com a descoberta de volumes de epístolas de Cícero por Petrarca, ${ }^{4}$ houve uma nova floração da ars dictaminis, de que serão exemplares os trabalhos de Erasmo de Roterdã, Brevissima formula (1520), e de Justo Lípsio, Epistolica institutio (1590). Uma característica marcante nessas novas artes é o abandono de algumas formalidades exigidas na composição epistolar medieval, que passaram a ser consideradas excessivas, consoante nos indica Erasmo (apud Tin, 2005, pp. 118-9):

Quão ridículos são aqueles que todas as cartas em saudação, exórdio, narração e conclusão dividem, e pensam que nelas consiste toda arte. Nem sempre é necessário usá-las todas juntamente, nem com frequência inteiramente e, como nos discursos, muitos mudam, conforme o caso, os tempos, a necessidade, a ocasião.

Visto que o foco deste texto é apresentar a correspondência de autoria de Vieira, torna-se necessário tecer algumas considerações acerca do lugar da epistolografia no âmbito da ordem religiosa a que ele pertencia. Criada em um tempo de acelerada expansão ultramarina (1540), a Companhia de Jesus refletia, em seus componentes e em sua distribuição geográfica, uma espécie de globalização avant

3 Uma tradução em português dessa obra, bem como das artes epistolares de Erasmo e Justo Lipsio, pode ser encontrada em Tin, 2005.

4

Destaque-se aqui, de passagem, que tal descoberta está diretamente relacionada à grande voga de imitação clássica nesse período, que teve seu ápice no ciceronianismo do início do século XVI, já foi amplamente estudado por Marc Fumaroli, na primeira parte de sua relevante obra sobre a "idade da eloquência” (1980). 
la lettre que caracterizava aquela época: oriundos de vários países europeus, seus integrantes logo se espalharam por Itália, Irlanda, Portugal, Espanha, França, além de Ásia, África e América do Sul, onde novos membros, autóctones, começaram a ser admitidos. Para manter a unidade e a comunicação com o centro romano da Companhia, implantou-se um instrumento fundamental: a correspondência epistolar, "coluna vertebral do corpo inaciano", nas palavras de Sheila Hue (2006, p. 14). A esse respeito, importa mencionar que o fundador da Ordem, Inácio de Loyola é autor de uma monumental correspondência, constituída por cerca de sete mil cartas, algumas das quais bastante extensas e minuciosas. Loyola, estabeleceu uma espécie de "pacto epistolar" com políticos, reis, pensadores, artistas e eclesiásticos, sempre trocando conselhos, preceitos, reivindicações, discutindo sobre matérias diversas, defendendo os princípios e a legitimidade de sua Companhia em todos os continentes em que esta se estabeleceu (cf. Bettiol, 2008, p. 26). Em alguns de seus textos, o religioso espanhol discorria sobre o modo adequado de redigir cartas, conforme se lê no seguinte trecho de caráter metaepistolar:

La carta principal yo la escribo una vez, narrando las cosas que muestran edificación, y después, mirando y corrigiendo, haciendo cuenta que todos la han de ver, torno a escribir o hacer escribir otra vez, porque lo que se escribe es aún mucho mas de mirar que lo que se habla; porque la escritura queda, y da siempre testimonio, y no se pude así soldar ni glosar tan fácilmente como cuando hablamos (Loyola, 1975, p. 687).

Sabe-se que um dos objetivos básicos das cartas jesuíticas era o controle interno da missão pelos superiores da Ordem em Roma, que exigiam relatórios minuciosos sobre a rotina diária dos padres e informações sobre possíveis causas de desânimos e crises. Assim, nesse eficiente sistema de comunicação, missionários disseminados pelo globo enviavam missivas para Roma, as quais eram copiadas e 
distribuídas pelas missões de modo que todos soubessem o que se fazia nesses variados lugares. Outro objetivo, segundo Adolfo Hansen, era o reforço do entusiasmo catequético por meio da remessa das cartas para outras missões, em que eram lidas como edificação (cf. Hansen, 2005, p. 16). Em síntese, essa surpreendente rede de comunicação global em pleno século XVI constituía um poderoso instrumento de informação e de divulgação das atividades da Companhia de Jesus.

Inserindo-se na longa tradição medieval da ars dictaminis, ${ }^{5}$ essas cartas trouxeram a diferença de serem geralmente redigidas em tom um pouco mais coloquial, procurando uma comunicação mais direta, sem muitos artifícios de retórica ou citações eruditas, e aplicando, nas palavras de Adolfo Hansen (2005, p. 26), "um aptum ou decorum específico da imitação do oral". Adotado por Loyola e seus seguidores, o modelo ${ }^{6}$ da missiva como uma conversação entre amigos, e não como discurso elaborado, atraiu o público leitor do período, o que se evidencia pelo grande número de traduções e edições das cartas jesuíticas, ${ }^{7}$ que afirmavam o poder e a expansão da Igreja Católica em tempos de Contrarreforma, além de saciar a curiosidade dos leitores acerca das novidades dos novos mundos (cf. Hue, 2006, p. 18).

Embora tendo motivado, ao longo do tempo, o interesse de pesquisadores de diferentes áreas do conhecimento, a correspondência de Vieira ainda aguarda uma edição crítica à altura da sua

5 Para as diversas variações no estilo epistolar ao longo do século XVII, ver Beugnot, 1994, pp.187-204.

6 Para um exame da estrutural formal das cartas jesuíticas e de sua ligação com a tradição da ars dictaminis, consultar Pécora, 2001, pp. 17-68.

7 Uma análise das diversas edições das epístolas inacianas nos séculos XVI e XVII foi feita por Lima, 1983. 
riqueza e da sua importância para a investigação de questões históricas, teológicas e políticas do século XVII. Destaque-se que toda a vida portuguesa do período da Restauração aí se encontra fotografada: enredos diplomáticos e intrigas palacianas, primazias políticas e questões religiosas, problemas militares e navais. Além da diversidade de temas tratados nas cartas, deve-se enfatizar a grande variedade de lugares em que se encontrava o remetente, que escreveu de Dover, Paris, Haia, Barcelona, Liorne, Roma, Porto, Coimbra, Lisboa, Alcanede, Carcavelos, Bahia ou Maranhão. É meritório igualmente destacar o perfil de seus destinatários aqui apresentados, tendo em vista uma ordem decrescente de distribuição do corpus textual, entre eles, segundo nos informa Carlos Maduro (2013, p. 60): nobres e diplomatas, clérigos e religiosos, reis e príncipes e cartas jesuíticas. A esse respeito, o referido estudioso do epistolário vieiriano ressalta uma desproporção assinalável em favor dos destinatários nobres e diplomatas, o que o faz concluir:

[...] Vieira gostava de falar com os homens do mundo acerca das coisas do mesmo mundo, servindo-se da carta para estar a par do que havia de novo. Com efeito, o jesuíta falou de tudo um pouco, na mais genuína tradição da retórica epistolar clássica de uma conversa entre amigos ausentes (Maduro, 2013, p. 61).

No que se refere à publicação dessa correspondência, assinale-se que a editio princeps, incompleta e com um texto mutilado pela censura, principalmente nas cartas em que o epistológrafo se refere aos cristãos-novos e ao Santo Ofício da Inquisição, data de 1735, quando se editaram dois volumes, organizados pelo Conde da Ericeira e pelo padre Antonio dos Reis, e dedicados ao Inquisidor Geral; o terceiro foi dado ao prelo em 1746, compilado pelo padre Francisco Antonio Monteiro. No Prólogo dessa edição, justifica-se a ausência de qualquer critério na ordenação das cartas, a partir de um 
argumento baseado no método escolhido pelo próprio jesuíta para a organização de seu sermonário tendo em vista o prelo:

[...] não se ordenarão estas cartas pela ordem rigorosa, e cronológica, em que foram escritas [...], porque ainda que os sucessos da vida deste Autor se percebem melhor nesta forma, como ela vai observada em cada uma das correspondências que, segundo o estilo comum, vão separadas, se percebem melhor, sem interromper-se os motivos, e os sucessos. Também não as dividi por matérias, por não alterar a referida suposição; e porque a variedade é mais agradável pelas razões sólidas, que dá o nosso Autor na primeira parte dos seus Sermões, quando no Prólogo se justifica de os não repartir pelas matérias, nem pela ordem dos tempos, e festas do ano (Vieira, 1735, s. p.).

Em 1854 e 1855, uma nova edição ampliada do epistolário vieiriano, apresentando 511 cartas, compôs os volumes XVI a XIX das Obras completas. Mantinha-se a mesma ordenação da edição anterior, que seguia apenas a ordem em que os originais chegaram à oficina do impressor, e apresentava, inclusive, a mesma repetição de textos. Arrumando as cartas em ordem cronológica e, com isso, evitando o problema das repetições, a edição seguinte foi feita pela Empresa Literária Fluminense, em dois volumes sem data, supostamente no ano de 1877. Entre 1925 e 1928, foi lançada uma importante edição das cartas de Vieira, num total de 719, divididas em três volumes que foram organizados por João Lúcio de Azevedo. Consultando as publicações anteriores, cópias manuscritas das cartas e os originais autógrafos a que teve acesso, o historiador português buscou apresentar uma publicação "menos viciada de imperfeições”, segundo nos esclarece na introdução, "reduzindo ao paradigma mais recente $^{8}$ as diferentes ortografias de três séculos" (Azevedo, 1970, p. XIV).

8 Para uma crítica da modernização da ortografia e da pontuação, presentes na edição preparada por Lúcio de Azevedo, cf. Révah, 1947, pp. 255-70. 
Durante várias décadas, essa relevante edição serviu de fonte principal de consulta para leitores e estudiosos da obra missivista do jesuíta. Cabe mencionar que até mesmo algumas iniciativas editoriais referentes à epistolografia vieiriana não fizeram mais do que reimprimir os textos fixados e anotados por Azevedo. No final da década de 1990, a ensaísta portuguesa Maria Lucília Pires (1997, p. 21) nos alertou para o fato de que "o estudioso de hoje, bendizendo embora o trabalho emérito do ilustre vieirista que foi Lúcio de Azevedo, tem ainda mais aguda consciência das limitações de sua edição". Dentre estas, ressalta o fato de o editor ter seguido frequentemente o texto da primeira edição, publicada, como se sabe, "sob as restrições do aparelho censório então em vigor, em casos em que os textos originais eram relativamente acessíveis" (p. 21).

É relevante mencionar a recente tentativa de superar as citadas limitações da edição organizada por Lúcio de Azevedo, com a Obra completa do Padre Antônio Vieira, dirigida por Jose Eduardo Franco e Pedro Calafate, que perfaz trinta volumes. No âmbito dessa publicação portuguesa, realizada entre 2013 e 2014, o tomo correspondente à epistolografia do jesuíta compreendeu cinco volumes nos quais se apresentam 758 cartas, dispostas em sequência cronológica, além de alguns textos apócrifos e outros de tipologia vária. Coordenada por Carlos Maduro, a equipe de pesquisadores, na qual me incluo, reuniu cronologicamente não apenas os textos publicados nas edições anteriores, mas também completou algumas das missivas mutiladas na primeira edição, reuniu cartas dispersas em diferentes publicações, traduziu um conjunto epistolar escrito em latim, que Vieira enviou a superiores da Companhia de Jesus em Roma, e publicou textos inéditos encontrados na Torre do Tombo e no Arquivo da Casa de Cadaval. Mesmo não se tratando de uma edição crítica, essa publicação fixou os textos com base em um conjunto expressivo de 
textos autógrafos e, quando estes não estavam disponíveis, foi feito um confronto "com edições manuscritas que se mantiveram muito próximas e muito fiéis aos documentos autógrafos", segundo nos esclarece o coordenador (Maduro, 2013, p. 44).

Nesta breve apresentação do epistolário vieiriano, importa ainda mencionar a existência de cartas e outros documentos cuja autoria é duvidosa - apesar de sua atribuição a Vieira em sua transmissão ao longo do tempo -, os quais foram publicados no quinto volume do tomo dedicado à epistolografia na Obra completa (2014). Cabe destacar que neles se pode perceber o desdobramento de matérias e questões abordadas pelo jesuíta em suas diversas intervenções tanto orais quanto escritas, que foram reapropriadas por autores anônimos, seja para emular suas ideias e formulações, seja para desqualificar o inaciano, atribuindo-lhe falsos depoimentos. Em alguns casos, esses documentos nos fornecem bons exemplos do pensamento dos que se opunham ao jesuíta; especificamente em relação aos textos que versam sobre a Inquisição e o judaísmo, eles nos facultam uma melhor compreensão da gravidade dos embates teológicos e políticos de sua época. Observa-se igualmente que, por vezes, os autores que se propuseram a imitar Vieira buscaram fazê-lo a partir de sua fama como orador eloquente, engenhoso e muito versado nas Letras; por esse motivo, empregaram uma linguagem afetada ou obscura, que, paradoxalmente, os afastou de uma faceta fulcral do estilo epistolar vieiriano: sua "simplicidade elegante" (Hansen, 2003, p. 39).

Cito como exemplo a carta apócrifa endereçada "A Jerónimo Sarrapante", publicada na edição da obra completa de Vieira (Carta 729 , t. I, vol. V, 2014), que constitui um exemplo patente de como ele era criticado por seus inimigos não apenas de voz, mas também por meio de "papeluchos satíricos", na expressão de Lúcio de Azevedo (t. II, 2008, p. 16). Devido ao grande número de cópias encontradas nas 
coleções da época, evidencia-se que se tornou bem conhecido um desses textos, escrito em forma de carta, supostamente assinada por Jerônimo Corrêa Sarrapante," "conhecido mentecapto, alvo das assuadas populares" (p. 16). O alvo principal da crítica era a intromissão de Vieira nos assuntos políticos de seu tempo. O texto apócrifo mencionado constitui uma breve resposta a essa carta, supostamente atribuída a Vieira, mas na realidade feita "por menos hábil foliculário", na correta avaliação de Lúcio de Azevedo (p.17), que corrobora a dúvida presente em nota ao manuscrito consultado para a edição portuguesa de 2014:

Não julgo este papel sendo de Vieira pelo estilo ser muito alheio, quanto mais que não costumava responder às coisas que faziam quem dizia que tinha juízo, quanto mais a quem estava louco. (Vieira, 2014, tomo I, vol. V, p. 169).

No esclarecedor prefácio de sua edição das cartas vieirianas enviadas do Brasil, Adolfo Hansen nos oferece orientações valiosas para tentar reduzir o anacronismo quase inevitável na retomada desses textos seiscentistas na atualidade. Em primeiro lugar, em relação ao remetente, deve-se atentar para o fato de se tratar de uma enunciação configurada como "racionalidade não psicológica de um tipo composto por paixões e caracteres subordinados como necessidade à hierarquia" (Hansen, 2003, p. 21). Considerando que a posição de Vieira como carteador é, antes de tudo, a de um tipo religioso subordinado às diretivas da Companhia de Jesus, o crítico nos apresenta uma síntese pertinente das diferentes posições institucionais desem-

\footnotetext{
9 "Carta que Jerônimo Corrêa Sarrapante escreveu a Antônio Vieira, estando preso por louco, no hospital o dito Sarrapante". Maquinações de Antônio Vieira jesuíta, Ms. da Biblioteca Nacional Portuguesa, t. 6, p. 231. Outras cópias desse texto são encontradas em diferentes códices dessa biblioteca.
} 
penhadas pelo inaciano que estão relacionadas ao decoro que rege suas missivas e aos diferentes matizes retóricos nelas configurados:

Tipo que, noviço, padre, mestre de retórica, teólogo, privado e valido de reis, amigo de aristocratas, inimigo da Inquisição, Superior de missão catequética, defensor de índios, afrontador de colonos, diplomata, orador sacro, profeta, não é uma subjetividade burguesa definida como unicidade de sujeito civil dotada de direitos liberais. Na sua representação como remetente, os interesses da monarquia e da Companhia de Jesus convergem, constituindo-o como tipo dotado de um caráter ou éthos principal, prudência, [...] que lhe controla o humor colérico legível em afetos secundários como raiva, desgosto, decepção, amargura, ironia (Hansen, 2003, pp. 21-2).

Desse modo, na maioria das vezes, os variados temas tratados em suas cartas se articulam diretamente aos acontecimentos que marcaram o seu tempo, ao lugar específico em que o remetente se encontrava no ato da escrita ou ao reino de Portugal em termos gerais. Dentre esses temas, se destacam: a invasão da Bahia pelos holandeses, a negociação com a França para formar uma liga anti-Espanha, a negociação com a Holanda para tratar da restituição de Pernambuco, o emprego do capital judaico na criação de companhias de comércio, o combate ao cativeiro dos índios, as viagens missionárias no Maranhão e Grão Pará, o poder da Companhia de Jesus sobre os aldeamentos indígenas, o processo inquisitorial e a vida no cárcere do Santo Ofício, a crise da lavoura açucareira, a febre amarela, o contrabando de ouro e prata, os preços monopolistas, a corrupção dos mercadores, a miséria dos pobres e o quilombo de Palmares.

Para os interessados nos seus célebres sermões, a leitura das cartas redigidas pelo inaciano possibilita o acesso a informações relevantes acerca do processo de reelaboração de sua oratória sacra para publicação, em correspondência enviada da corte, onde organi- 
zou os primeiros tomos, e do Brasil, de onde os diferentes volumes de seu sermonário, seguiam na frota para Portugal, "entre o mascavado do açúcar ou fumo do tabaco" (Vieira, 2013, t. I, vol. IV, p. 476), encaminhando-se ao prelo. Leiamos alguns exemplos. Em carta de 1678 a Duarte Ribeiro Macedo, afirma:

Pergunta-me Vossa Senhoria em que estado vai a estampa dos meus sermões, e digo que caminha com pressa, e com a oficina, que é de João da Costa, o francês, posta neste Colégio, e não há dúvida que sairá muito correta. O segundo tomo já está acabado e entro pelo terceiro, mas não poderão sair na mesma forma porque alguns dos sermões são do tempo da guerra, e não quero que se ofendam esses senhores da que já escreveram lhes faziam as minhas exortações. Se Deus der vida, matéria tenho deste gênero para mais de doze tomos [...] (p. 168).

Um tema recorrente em relação a essa publicação, portanto, é a necessidade de trabalhar as anotações de que dispunha, referentes a cada pregação especifica, para transformá-las em texto publicável, como se lê na seguinte carta de 1689, endereçada a Sebastião de Matos e Sousa: "Vossa Mercê, pela mercê que faz aos meus borrões, me insta a que os dê à estampa, o que não pode ser sem os alimpar primeiro; e com a joeira não ser muito fina, tudo se me vai em alimpaduras" (p. 405). E mais, em carta de 1683 a Diogo Marchão Temudo: "é só o que me obriga a tomar nos meus anos um tão molesto trabalho, como o de pôr os borrões em estilo que se possam ler" (p. 300).

Em síntese, o exame das cartas vieirianas permite comprovar a grande contribuição da epistolografia de Antônio Vieira não só para o conhecimento mais aprofundado de seu sermonário como também de aspectos decisivos da história do século em que ele viveu, consoante nos indica Maria Lucília Pires (1997, pp. 24-5):

Se é certo que as cartas de Vieira nos dão a imagem de um homem apaixonado por várias causas, política (no seu sentido eti- 
mológico) é talvez a palavra que unifica os diversos objetos da sua paixão. $\mathrm{O}$ apaixonado empenhamento de Vieira nas questões políticas, expresso na ação e na escrita, unifica no seu pensamento o pendor pragmático e a utopia messiânica, ilumina as diversas facetas da sua vida.

Ao leitor, portanto, um convite para a leitura das cartas de Antônio Vieira, tão obscurecidas pelo sucesso obtido por seus sermões quanto iluminadoras de importantes facetas da vida e da obra do jesuíta. 


\section{Referências}

AZEVEDO, João L. de. História de Antônio Vieira. 2 t. São Paulo: Alameda, 2008.

"Introdução". In VIEIRA, Antonio. Cartas. Coordenadas e anotadas por J. Lúcio de Azevedo. Lisboa: Imprensa Nacional, 1997, vol. I, pp. IX-XVI.

BETTIOL, Maria Regina B. A escritura do intervalo: a poética epistolar de Antônio Vieira. São Leopoldo: Editora da Unisinos, 2008.

FUMAROLI, Marc. Lâge de léloquence: rhétorique et "res literaria" de la Renaissance au seuil de lépoque classique. Paris: Albin Michel, 1980.

HANSEN, João A. "A escrita da conversão". In CONSTIGAN, Lúcia H. (org.) Diálogos da conversão. Campinas: Editora da Unicamp, 2005.

. "Introdução". In VIEIRA, Antônio. Cartas do Brasil. Organização de João Adolfo Hansen. São Paulo: Hedra, 2003. pp. 7-74.

HUE, Sheila Moura. "Introdução". Primeiras cartas do Brasil: 15511555. Rio de Janeiro, Jorge Zahar, 2006.

LIMA, Durval P. de. "As cartas dos jesuítas". Separata da Revista da Biblioteca Nacional n. ${ }^{\circ}$ 1-2. Lisboa, 1983, pp. 215-43.

MADURO, Carlos. "Introdução geral à epistolografia". In VIEIRA, Antonio. Obra completa Padre Antonio Vieira. Dir. José Eduardo Franco e Pedro Calafate. Lisboa: Círculo de Leitores, 2013, t. I, vol. 1. 
MURPHY, James J. Rhetoric in the Middle Ages: A History of Rhetorical Theory from Saint Augustine to the Renaissance. 6 ed. Berkeley, Los Angeles e Londres: University of California Press, 1990.

OLIVEIRA, Ana L. de. "As diferentes versões da Carta ânua de Antônio Vieira”. Ideação, vol. 2, n. 20, pp. 137-54, Feira de Santana, jul./ dez. 2008.

PECORA, Alcir. “A arte das cartas jesuíticas no Brasil”. In Máquina de gêneros. São Paulo: EdUSP, 2001.

PIRES, Maria Lucília G. "A epistolografia de Vieira. Perspectivas de leitura”. In MENDES, M. V. et al. (orgs.) Vieira escritor. Lisboa: Cosmos, 1997, pp. 21-30.

RÉVAH, I. S. "Petite contribution à la future édition des lettres du Père Antonio Vieira”. In Bulletin des Etudes Portugaises et de l'Institut Français au Portugal, t. XI. Coimbra: Coimbra Editora, 1947, pp. 255-70.

TIN, Emerson. A arte de escrever cartas. Campinas: Editora da Unicamp, 2005.

VIEIRA, Antonio. Obra completa Padre Antonio Vieira. Dir. José Eduardo Franco e Pedro Calafate. Lisboa: Círculo de Leitores, 20132014, vol. 30 .

. Cartas. Coordenadas e anotadas por J. Lúcio de Azevedo.

Lisboa: Imprensa Nacional, 1997, vol. 3.

. Cartas do Pe. Antonio Vieira da Companhia de Jesus. Lisboa Ocidental: Oficina da Congregação do Oratório, 1735-1746, vol. 3. . Cartas do padre Antonio Vieira. Lisboa: J. M. C. SEABRA e T. Q. Antunes, 1854-1855, 4 t., vol 2. 